\title{
Lessons Offered by the United States' Experience in Integrating Students with Intellectual Disability into Postsecondary Education
}

\section{* Areej Almutairi \\ * Norimune Kawai \\ * Abeer Alharbi}

\begin{abstract}
The United States began integrating students with intellectual disability into postsecondary education in the late 1970s. This integration was inspired by the research on effective educational practices. Following the results of this research, federal laws were enacted, requiring colleges and universities to make postsecondary education available to persons with intellectual disability to help gain employment. This study aims to explore the US' experience with inclusive higher education and summarizes the positive outcomes of the initiatives undertaken by the US. Single qualitative design was used in the current study to review the relevant literature and data from the US. We analyzed the useful lessons offered by the educational experiences and the subsequent employment gain with respect to the case of the US, which could encourage other nations to take similar steps. This article provides valuable insights that can form the basis for formulating a prescriptive theoretical model by researchers and policymakers interested in laying the foundation for successful integration of students with intellectual disability into higher education.
\end{abstract}

Keywords: integration, intellectual disability, postsecondary education, inclusive higher education (IHE), developmental disability

$$
\text { الملاخص }
$$

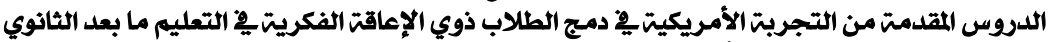

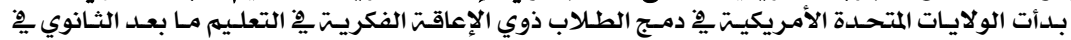

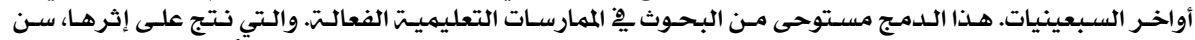

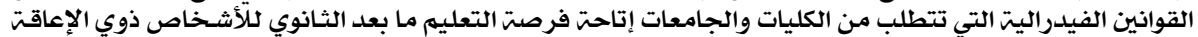

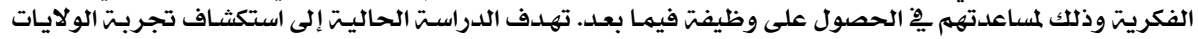

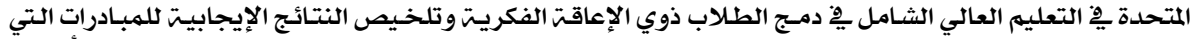

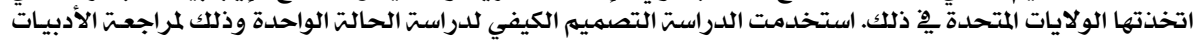

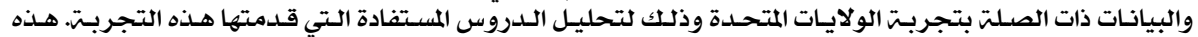

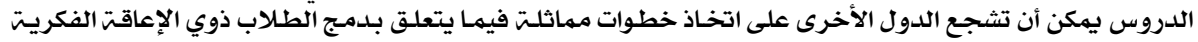

* lecturer at Special Education Department, College of Education, King Saud University, Riyadh City, Saudi Arabia. A doctoral student, Graduate School for International Cooperation and Development, Hiroshima University, HigashiHiroshima, Japan.

* Full Professor at Department of Special Needs Education, Graduate School of Education, Hiroshima University, Higashi-Hiroshima, Japan.

* Assistant Professor at Special Education Department, College of Education, King Saud University, Riyadh City, Saudi Arabia 
Lessons Offered by the United States' Experience in Integrating Students with Intellectual Disability

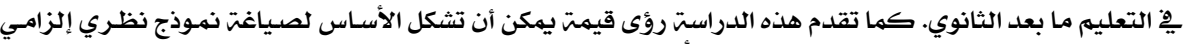

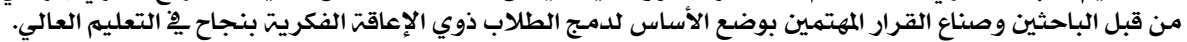

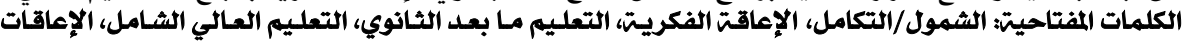

\section{Introduction}

Imparting postsecondary education (PSE) to persons with intellectual disability (ID) is considered as a good way to make a difference in the lives of persons with ID (Cook, Hayde, Wilczenski, \& Poynton, 2015). According to Francis et al. (2018), obtaining a university education results in positive outcomes in terms of gaining employment, independent living, and community participation for people with and without intellectual disability. It is no surprise that the focus of the conversation has shifted from "Should students with intellectual disabilities go to college?"(Grigal, Hart, \& Lewis,2010,p. 7) to "How can students with intellectual disabilities go to college?" (Grigal, Hart, \& Lewis, 2010, p. 7).

Presently, there are over 200 PSE programs for students with ID across the US (Think College National Coordinating Center, 2019). The numbers of these programs have almost doubled since 2009 and will continue to increase (Kelley \& Westling, 2019) due to the public and private efforts to provide PSE opportunities for persons with ID. Plotner and Marshall (2015) reported that legal and financial supports, as well as increasingly progressive attitudes toward persons with ID, have contributed toward the expansion of PSE programs for these students across the US. The increase in the numbers of PSE programs for persons with ID and participation from students demonstrate the advances that the US has made in the sphere of inclusive education since the passing of the Rehabilitation Act of 1973 (Jester, 2016).

Prior research studies have investigated a variety of aspects pertaining the field of PSE for persons with ID in the US. However, limited research studies have been conducted with respect to lessons offered from the experience of the US in integrating students with ID into PSE. For example, Walker (2014), and Plotner and Marshall (2014) reviewed the US disability legislation that helps students with 
ID access colleges and universities. They also noted several problems in the nature of PSE programs, accepting students with ID in PSE that need to be addressed for the well-being of students with ID. Thus, it would be fair to state that there are research gaps pertaining to the exploration of different aspects of providing PSE for persons with ID in the US. The current study provides an overview of the lessons offered by the US experience of integrating students with ID into PSE and acts as an introductory guide for interested researchers, decision-makers, and other stakeholders to engage with the several issues that exist with regard to PSE for students with ID.

In this paper, we attempt to offer insights that can facilitate the creation of prescriptive models on the part of researchers and policymakers in other countries engaged in laying the foundations for the integration of students with ID into PSE. This paper aims to analyze the measures taken in the US to integrate persons with ID into PSE. The sustained US experience provides a road map for future research work and the implementation of measures to integrate persons with ID into PSE. This paper divides the broader subject of the lessons offered by the US experience into various aspects for further exploration: educational laws supporting PSE for people with ID in the US, financial support for students with ID in the US, status of research in the field, and the issues PSE systems face when integrating students with ID.

\section{Methods}

\section{Study design}

This study aims to identify the lessons offered by the US' experience in integrating students with ID into higher education. Drawing from Yin's (2018) exhaustive research on case study design and methods, this study is designed as follows: formulation of research question and objective in the start, followed by the formulation of predictive proposition, and then the presentation of an exploratory, single, and holistic qualitative case study. This kind of a design helps in exploring a complex phenomenon that has not been 
Lessons Offered by the United States' Experience in Integrating Students with Intellectual Disability into Postsecondary Education Areej Almutairi Norimune Kawai Abeer Alharbi

investigated and in formulating an in-depth description of the phenomenon (Yin, 2018, Merriam \& Tisdell, 2016).

\section{Formulating a predictive proposition}

Yin (2018) puts forth that making theoretically predictive propositions in a case study can be beneficial in guiding design, data collection, and in laying a foundation to make analytical generalizations. As a result, in this study we make a theoretically predictive proposition based on our experiences of researching on the subject of PSE for persons with ID in the US. We propose that the experience of the US in integrating students with ID into PSE is a result of the government support provided to colleges, the enactment of laws that support persons with ID, financial support to persons with ID, and the continued research on inclusive higher education. This holistic predictive proposition is examined in this study.

\section{Data collection procedure}

The search for literature was carried out using Googol Scholar, ERIC, and Think College resources. The key terms determined for search were PSE, college, university, students with ID, and persons with ID. The search was narrowed down to only include studies published between 2010 and 2019. Scholar journals, reports, theses, dissertations, and handbooks were included in the reviewed literature. A narrative literature review was carried out based on selecting the following search criteria: research studies were written in English, research studies were published in the past 10 years, and studies that focused only on PSE for persons with ID or students with ID. Initially, we conducted a general review of literature on the subject, not restricting our focus only to the literature on the US, to reduce potential research biases and to identify how many publications are available in the field of PSE for persons with ID from different countries. While the results for publications from countries such as Italy, Ireland, Australia, and Irish were found to be few, the publications in Canada were much better and available. 
A total of 17,200 search results were found. In the first phase of screening, we reviewed all the search results by screening the title of each study, resulting in the exclusion of 17,130 studies that did not meet the inclusion criteria concerning search keywords. Only 70 studies were found to be relevant. In the second phase, we screened the abstract and conclusion of all the 70 papers to ensure that the inclusion criteria were met. There was also an emphasis that the studies were conducted in the US. 54 studies were excluded in this phase, with only 16 studies found to be meeting the respective inclusion criteria. Following which, we synthesized the findings of these studies based on their similarities and compared the synthesis with the theoretical propositions put forth by us in this study (Table 1). The excluded studies were ones that were not written in English, ones that examined the impact of PSE programs on students with ID, were not focused mainly on persons with ID in PSE, and were not conducted within the US.

Table 1 :- Categorization of studies included for the review

\begin{tabular}{|c|c|c|c|c|}
\hline Authors & Year & Type & Source & Theme \\
\hline $\begin{array}{c}\text { Grigal, Hart, and } \\
\text { Papay }\end{array}$ & 2019 & Book & $\begin{array}{l}\text { Koninklijke Brill, NV: } \\
\text { Leiden. }\end{array}$ & \multirow{7}{*}{$\begin{array}{c}\text { The role of } \\
\text { educational } \\
\text { laws }\end{array}$} \\
\hline Jester & 2016 & Dissertation & University of Florida, & \\
\hline Jones et al., & 2015 & Report & Think College & \\
\hline $\begin{array}{c}\text { Gibbons, Cihak, } \\
\text { Mynatt, \& Wilhoit, }\end{array}$ & 2015 & $\begin{array}{l}\text { Research } \\
\text { Article }\end{array}$ & $\begin{array}{c}\text { Journal of } \\
\text { Postsecondary } \\
\text { Education and } \\
\text { Disability }\end{array}$ & \\
\hline Griffin \& Papay, & 2017 & Report & Think College & \\
\hline $\begin{array}{c}\text { Grigal, Hart, and } \\
\text { Weir }\end{array}$ & 2013 & Report & Think College & \\
\hline Papay et al., & 2017 & Report & Think College & \\
\hline Grigal \& Papay, & 2018 & $\begin{array}{l}\text { Research } \\
\text { Article }\end{array}$ & $\begin{array}{c}\text { New Directions for } \\
\text { Adult and Continuing } \\
\text { Education }\end{array}$ & $\begin{array}{l}\text { Financial } \\
\text { assistance }\end{array}$ \\
\hline
\end{tabular}


Lessons Offered by the United States' Experience in Integrating Students with Intellectual Disability into Postsecondary Education Areej Almutairi Norimune Kawai Abeer Alharbi

\begin{tabular}{|c|c|c|c|c|}
\hline Grigal et al., & 2013 & Report & Think College & \\
\hline Snyder \& Dillow, & 2011 & Report & $\begin{array}{l}\text { Institute of Education } \\
\text { Science, U.S. } \\
\text { Department of } \\
\text { Education }\end{array}$ & \\
\hline Grigal et al., & 2013 & Report & Think College & \\
\hline Grigal et al., & 2019 & Book & $\begin{array}{l}\text { Koninklijke Brill, NV: } \\
\text { Leiden. }\end{array}$ & \multirow[t]{5}{*}{$\begin{array}{l}\text { Continuing } \\
\text { research }\end{array}$} \\
\hline Snyder \& Dillow & 2011 & Report & \begin{tabular}{|} 
Institute of Education \\
Science, U.S. \\
Department of \\
Education \\
\end{tabular} & \\
\hline $\begin{array}{l}\text { Kleinert, Jones, } \\
\text { Sheppard-Jones, } \\
\text { Harp, \& Harrison }\end{array}$ & 2012 & $\begin{array}{l}\text { Research } \\
\text { Article }\end{array}$ & $\begin{array}{c}\text { Teaching Exceptional } \\
\text { Children }\end{array}$ & \\
\hline $\begin{array}{l}\text { Think College } \\
\text { National } \\
\text { Coordinating } \\
\text { Center } \\
\end{array}$ & 2019 & Report & Think College & \\
\hline Plotner \& Marshall & 2014 & $\begin{array}{l}\text { Research } \\
\text { Article }\end{array}$ & $\begin{array}{c}\text { Journal of Disability } \\
\text { Policy Studies }\end{array}$ & \\
\hline Grigal \& Hart & 2010 & Book & $\begin{array}{c}\text { Baltimore, MD: Paul } \\
\text { H. Brookes Publishing } \\
\text { Co. }\end{array}$ & \multirow[t]{7}{*}{ Issues in PSE } \\
\hline Plotner \& Marshall & 2015 & $\begin{array}{l}\text { Research } \\
\text { Article }\end{array}$ & $\begin{array}{c}\text { Intellectual and } \\
\text { Developmental } \\
\text { Disabilities Journal }\end{array}$ & \\
\hline Walker & 2014 & $\begin{array}{l}\text { Research } \\
\text { Article }\end{array}$ & $\begin{array}{c}\text { Northwestern Journal } \\
\text { of International } \\
\text { Human Rights }\end{array}$ & \\
\hline Moore & 2014 & Dissertation & $\begin{array}{c}\text { Grand Valley State } \\
\text { University }\end{array}$ & \\
\hline Grigal et al. & 2019 & Book & $\begin{array}{c}\text { Koninklijke Brill, NV: } \\
\text { Leiden }\end{array}$ & \\
\hline Grigal et al. & 2010 & Report & Think College & \\
\hline Grigal et al. & 2013 & Report & Think College & \\
\hline
\end{tabular}




\section{Data analysis}

A thematic analysis was conducted through data coding and grouping the studies into themes. Drawing from the study by Braun and Clarke (2006), the data analysis was executed through the following phases:

1. Phase 1: familiarizing with the data

2. Phase 2: generating initial codes

3. Phase 3: searching for themes

4. Phase 4: reviewing themes

5. Phase 5: defining and naming themes

6. Phase 6: producing the report

Following which, drawing from the study by Yin (2018), the linking of the findings from data analysis with the theoretical proposition was carried out by using a pattern matching technique. The linking was carried out by comparing the current study findings with the predicted proposition. We compared our predictive proposition with the findings of literature review to check if the proposition corresponds with the literature review findings. If the predictive proposition is supported by the findings of literature review, it would strengthen the study and enhance the internal validity of the case study.

\section{Trustworthiness and credibility}

The procedures for this study were based on the studies by Brantlinger, Jimenez, Klingner, Pugach, and Richardson (2005) and Merriam and Tisdell (2016) to ensure trustworthiness and credibility of the data. To quote Brewer and Movahedazarhouligh $(2019$, p.6) to explain the next step, "The biases were systematically checked throughout the analysis process by questioning and returning to the 
Lessons Offered by the United States' Experience in Integrating Students with Intellectual Disability into Postsecondary Education Areej Almutairi Norimune Kawai Abeer Alharbi

data to back up the claims." Following which, researcher triangulation was used, wherein multiple researchers checked the results of the study and made changes. A full-fledged and detailed description of the case was also conducted to minimize biases. In addition, the researchers required a colleague to review the results of the final study, called the peer examination. The examination was acknowledged by the researchers; as they understood the effect their assumptions, beliefs, values, and biases have on the interpretation of data and the conclusion of the study (researcher reflexivity).

\section{Results}

The final findings of this study are presented as lessons offered by the US' experience in integrating ID students into PSE. The analyses of several themes pertaining the subject are as follows:

\section{The role of educational laws}

According to Mercier (2017), for a thorough understanding of the PSE experiences of students with ID, it is essential to consider the special education laws that have been enacted to support this group. Grigal et al. (2019) pointed out that community initiatives and federal and state legislative directives have led to increased opportunities for students with ID to pursue higher education. In the US, students with ID have more opportunities of accessing PSE than earlier. A significant credit goes to the enactment of laws such as those mentioned below. Legislators recognized the need to amend the laws in order to support ID students pursue higher education (Jester, 2016). The American legislation emphasizes the inclusion of students with ID into college classes, internships, and as well as into the academic and social environments of college. Courtesy the progressive laws, students with ID have access to comprehensive transition programs (CTPS), wherein they can acquire a variety of skills including academic, professional, and independent living skills, all of which they also use in the workplace (National Parent Center on Transition and Employment, 2019). Moreover, federal legislations have been amended so that more PSE programs are available 
for students with ID (Jones et al., 2015). The availability of these programs increased by at least 60\% between 2009 and 2011 (Hart, Grigal, \& Weir, 2010). While 64\% of the students with ID were enrolled in four-year university or college programs, $36 \%$ were attending higher education institutions with two-year courses. Moreover, $61 \%$ of students with ID obtained a paid job after completing their higher education program (Papay, Trivedi, Smith, \& Grigal, 2017).

The Individuals with Disabilities Education Act of 2004 (IDEA) is an important law that supports PSE for such students; it improves the transition process from secondary to PSE and then into the workplace. Meanwhile, the Americans with Disabilities Act of 1990 (ADA) calls for the provision of appropriate accommodations for students with ID so that they could gain access to learning and work opportunities (Gibbons et al., 2015). Finally, the Higher Education Opportunity Act of 2008 (HEOA) has been critical in ensuring that the students with ID have opportunities to enroll in PSE (Mercier, 2017), can receive financial aid through government grants, and can access study-based work programs (Gibbons et al., 2015). Moreover, the HEOA outlines critical elements that the PSE programs should include for these students, which would ultimately lead to profitable employment (Mercier, 2017).

The successful development and expansion of PSE programs for students with ID in the US required federal support through legislation (Griffin \& Papay, 2017). According to Grigal et al. (2013), the enactment of legislation and educational policies have led to better practices and research in inclusive higher education, determined the nature of funding and service standards, and created new paths to identify critical issues in legislations and policies, and existing practices related to PSE for persons with ID. Legislations and laws such as IDEA and HEOA have enabled substantial support and services for this group and have encouraged interagency cooperation and research that facilitate team cooperation, which helps in serving 
Lessons Offered by the United States' Experience in Integrating Students with Intellectual Disability into Postsecondary Education Areej Almutairi Norimune Kawai Abeer Alharbi

these persons. Legislations have definitely had an impact on the federal and state policies of the US.

Laws are the backbone for any initiative that guarantees rights and protects activities, even if these laws face opposition. Scior (2011)mentions that public attitudes toward persons with ID affect the success or failure of policies aimed at integrating these individuals into society. Tyler (1990) concludes that most people believe that laws should be obeyed. Thus, the first lesson offered by the US' experience in integrating people with ID into PSE is that the enactment of laws and legislation related to educational/social initiatives is an important step in facilitating awareness among people about the needs of persons with ID to access higher education, as emphasized by Grigal et al., (2019).

\section{Financial assistance}

The primary purpose for enforcing the abovementioned US laws is to protect persons with disabilities, including people with ID from discrimination and to remove the obstacles on their path toward inclusion in society. However, enacting laws alone is not enough to guarantee an initiative success, financial support is also necessary for the successful execution of an initiative. Federal funding is an essential source of support for promoting and developing PSE programs for students with ID. For example, Transition and Postsecondary Programs for Students with Intellectual Disability (TPSID) are model demonstration programs. The Office of Postsecondary Education contributed toward increasing the number of inclusive PSE programs for students with ID in 88 different campuses (Papay et al., 2017) and more than 2,700 students with ID have studied in campuses through TPSID programs (Grigal \& Papay, 2018). Moreover, 31 states were awarded TPSIDs for the 2010-2020 period, 27 states had 77 comprehensive transition and postsecondary programs, and 28 states established relevant coordination roles at the state level (Think College National Coordinating Center, 2019). This increase in the number of students with ID enrolled in higher education is due to the growth of program options. The numbers of 
these programs have increased by $78 \%$ since 2008 , the year when the HEOA was passed (Grigal \& Papay, 2018) (see Figure 1).

300

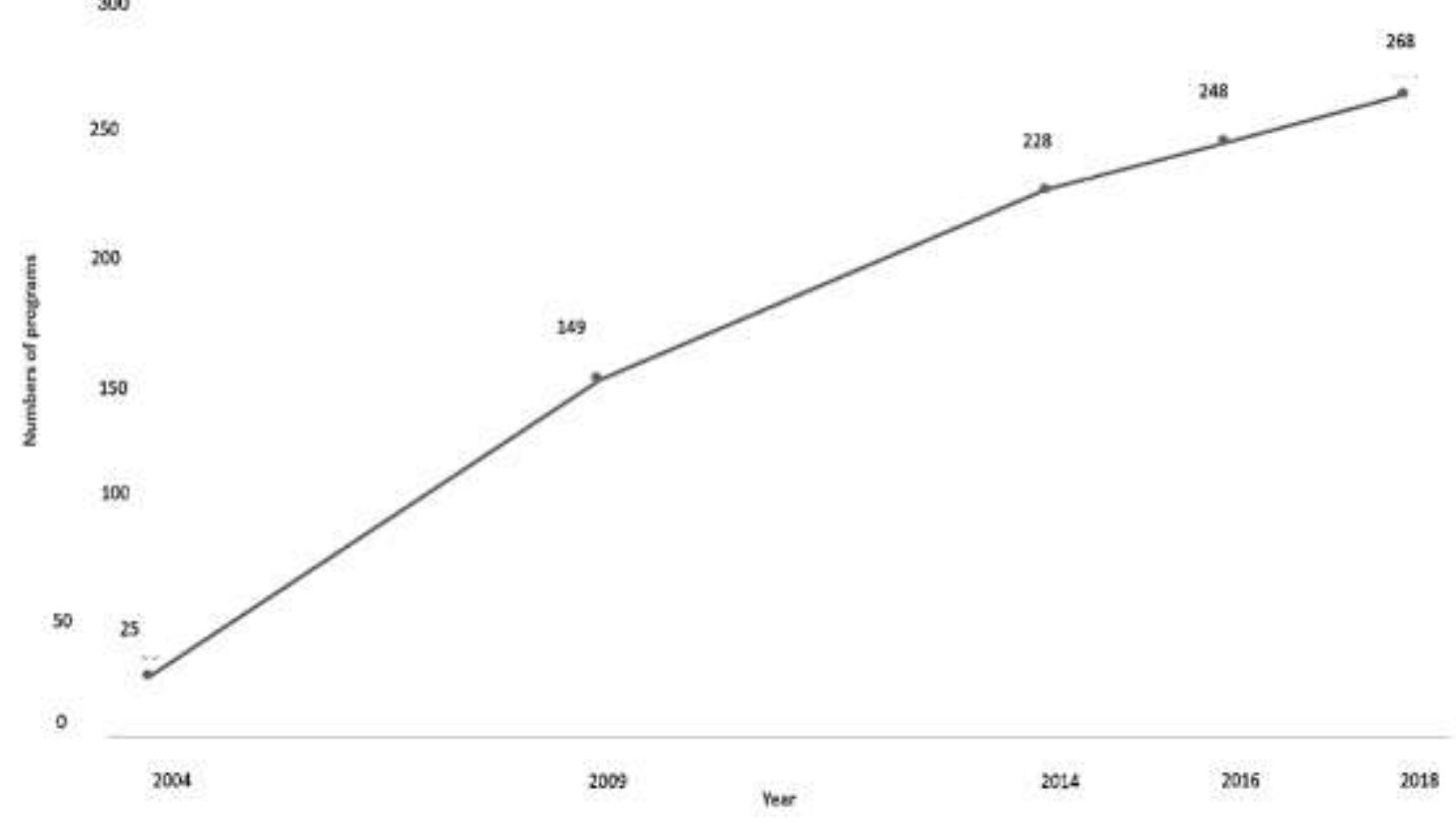

Figure 1. Growth in higher education programs for students with ID in the United States during the 2004-2018 period

(Grigal \& Papay, 2018, p.7)

When PSE programs for students with ID first emerged, federal and state governments provided substantial support for the establishment of inclusive higher education programs. For example, in 2010, the Office of Postsecondary Education provided nearly 11 million US dollars for model demonstration programs to 27 US universities and colleges to establish PSE programs for students with ID (Grigal et al., 2013). Moreover, grants were provided to 25 US universities and colleges in 19 states from 2015 to 2020 (Think College National Coordinating Center, 2019). While the US spent approximately 3 million US dollars on PSE in 1970, it spent more than 
Lessons Offered by the United States' Experience in Integrating Students with Intellectual Disability

47 million US dollars on PSE in 2010 across all state departments and agencies (Snyder \& Dillow, 2011).

Thus, by enacting laws and legislations to integrate students with ID into inclusive university and college education, and by providing the necessary financial support, the US has successfully implemented PSE programs for students with ID. The essential connection between the legislations and funding are crucial lessons that can be drawn from the US experience.

\section{Continuing research}

Grigal et al. (2013) observed that increasing the number of college options for students with ID led to an increase in the number of students with ID enrolling in colleges and improved researchers' ability to conduct investigations of their experiences. In addition, since the passage of HEOA, there has been considerable growth in various research on higher education for persons with ID (Grigal et al., 2019).

Researchers have relied on secondary analyses of available data collections, national surveys, data analyses from the National Focal Point and the TPSID model demonstration programs, and several qualitative studies on different subjects of PSE for individuals with ID (Grigal et al., 2013). Since the higher educational institutions started creating PSE models for students with ID (Grigal, Hart, \& Weir, 2012), there has been a surge in the number of papers on the subject. The total number of PSE research studies conducted in higher educational institutions in the US in 2010 was 6,632 (Snyder \& Dillow, 2011).

One of the fundament contributions toward PSE for persons with ID comes from Think College. The Think College National Coordinating Center was established in 2010 and it provides support, coordination, and evaluation services for students with ID in PSE. It also facilitates research within this population and is a project allied with the Institute for Community Inclusion at the University of 
Massachusetts. Think College is dedicated toward developing, expanding, and improving research and practices in inclusive higher education for people with ID (Think College.net) and has contributed significantly to the field. Think College is funded by the HEOA and grants from the Office of Postsecondary Education in the US Department of Education (Kleinert et al., 2012; Think College National Coordinating Center, 2019).

Moreover, Think College maintains an accessible online database that provides details of PSE programs for students with ID across the US (Cook et al., 2015). The college aims to produce and share knowledge and information by creating links between the research and practice, which is an essential element for making progress in this area. It has conducted research on higher education improvement along with providing many comprehensive training and technical assistance activities, face-to-face or online projects, and resources that are distributed through social media, webinars, and publications to inform and support stakeholders. Think College is a resource center for stakeholders including families, professionals, and students, for it is founded on the belief that sustainable change takes place when all are involved. Furthermore, Think College believes that effective policies must be linked to current initiatives and practices. Therefore, this institution works with experts on educational issues and the development of legislative policies, and deals with federal and state government leaders to provide evidencebased information that will help them improve existing policies (Think College National Coordinating Center, 2019).

After the introduction of legislation and financial support to facilitate the implementation of an initiative, conducting research and studies, and establishing a center to support and serve an initiative are the significant steps that are required to be taken. These will help in tracking progress or delays and can also be used to assess programs and share information with others. A critical analysis of the research efforts in promoting PES initiatives, the documentation of 
Lessons Offered by the United States' Experience in Integrating Students with Intellectual Disability into Postsecondary Education Areej Almutairi Norimune Kawai Abeer Alharbi

their evolution, and the issues that may impede the initiatives in the US can serve as a good guide for international researchers.

\section{Issues in PSE}

Despite the US efforts to integrate students with ID into higher education, some issues and shortcomings remain. Some of the biggest challenges the US faces in implementing PSE measures for students with ID include the eligibility criteria for accepting these students into higher educational institutions and the options available for access (Plotner \& Marshall, 2014; Grigal \& Hart, 2010). Students with ID may not meet the traditional academic criteria for admission in universities and colleges. In turn, higher education institutions may be unable to provide the support that is needed (Plotner \& Marshall, 2015 ). Denying admission may be reasonable if alternative programs are available to meet a student's abilities. However, a justification for rejecting someone wishing to pursue higher education can be made on the ground that there are programs available for students with ID along with government funding (Walker, 2014).

There may be a case that there is no clear information on PSE programs offered to students with ID, that the nature of these programs is heterogeneous concerning educational style, structures, practicalities, and learning environments (Plotner \& Marshall, 2014). The lack of similarity among these programs leads to a lack of clarity and knowledge regarding their common denominators and in turn results in difficulty to determine the type of program that is most efficient for a person with ID (Moore, 2014). In addition, although there are many PSE programs for students with ID, most programs do not integrate the ID students with peers who do not have disabilities, which could negatively affect the interaction between students with ID and other students in PSE. Interpersonal communication is an essential aspect of the higher education experience for both students with ID and students without disabilities. As a result, when students with ID are segregated, the gap between them and other students 
without disabilities increases, with the creation of further obstacles (Walker, 2014).

Furthermore, segregating students with ID may make them feel unequal to other students because they cannot participate with them in the same class and may adversely affect their self-esteem (Walker, 2014). This demonstrates the necessity for inclusive educational programs for students with ID at all educational stages. In the US, inclusive higher education programs are also important owing to the contribution they make to the value of the PSE experience for all students, not just the students with ID, as both groups of students can achieve better results in academic and personal skills, employment, independence, self-advocacy, and selfconfidence (Grigal, Hart, \& Weir, 2011; Hart et al., 2010). More importantly, these students with ID will also experience social acceptance while participating in courses, clubs, and other extracurricular activities with their peers without disabilities (Jester, 2016); wherein they can see themselves as similar to students without disabilities, leading to increase in their self-esteem (Grigal et al., 2011; Hart et al., 2010).

Most of the existing research studies on PSE for students with ID are either descriptive, qualitative, or based upon case studies. Effective practical research is challenging because most of these programs have been recently implemented. Systematic comparisons of PSE programs' outcomes for individuals with ID are still scarce. Some programs and services in PSE are available to students without federal legislation, financial support, or regulatory directives. As a result, it is difficult to recognize such practices as meaningful owing to the lack of evidence-based practices in the area of PSE programs for persons with ID. In addition, there is the issue of disassembled efforts to fund research in the field of PSE for students with ID (Grigal et al., 2019; Grigal et al., 2010).

Moreover, while some PSE programs for persons with ID focus on inclusive courses, others concentrate on employment and social courses, making it difficult to track the effect of inclusive higher 
Lessons Offered by the United States' Experience in Integrating Students with Intellectual Disability into Postsecondary Education Areej Almutairi Norimune Kawai Abeer Alharbi

education experience for these students. There is also a lack of data related to long-term program outcomes such as sustained competitive employment or independent living. Indeed, the financial support for research in this area has been limited and falls within a narrow range of the study (Grigal et al., 2010; Grigal et al., 2019).

Grigal et al. (2013) commented further on the current practices in PSE for students with ID. They report that credentials in PSE programs differ from one another concerning their roles and attributions, wherein there is no reliable fixed basis for these programs. Therefore, an accreditation criterion needs to be established to help PSE programs determine the quality of work, services, and student outcomes. There is also a necessity for the federal funding to come from sources other than the Office of Postsecondary Education in order to expand PSE programs and further evaluate their efforts. In addition, PSE programs currently operate independently of employment initiatives, and this is an area that can be reformed via partnerships between PSE programs and government vocational rehabilitation agencies. Partnerships would support the programs and serve as follow-ups on students' progress and results. Other countries may also face the challenges mentioned above on their path to implementing inclusive education for students with ID (Walker, 2014).

\section{Discussion}

The comparison made between the predictive proposition and the findings of the literature review in this study proved useful in exploring the research conducted by other researchers in the field of PSE. The comparison helped explore the contributions made by other countries concerning the integration of persons with ID into PSE. We also found few similarities between the US experiences of integrating persons with ID into PSE with the experiences of other countries researched. 
While our proposition could have been divided into three subpropositions, we however, acknowledged that the US experience in integrating persons with ID into PSE is broader than the three aspects of educational laws, financial support, and ongoing research. For instance, we also understood how important interagency cooperation is with respect to the US experience of integrating persons with ID into PSE. Thus, we formulated a broader proposition to ensure that our study captures all these important facets of the respective area.

The findings of the studies reviewed were consistent with the theoretical proposition; that is the experience of the US in integrating students with ID into PSE is a result of the government support provided to colleges, including the enactment of laws and legislations that support persons with ID, financial support, and the continued publication of research in inclusive higher education. Grigal et al.'s (2019) evaluation description report of the inclusive higher education for persons with ID in the US was consistent with some of the findings of this study, including the findings on federal laws, research, and issues in PSE. These authors discussed a variety of topics such as types of PSE programs for people with ID, TPSID, PSE credentials, and issues in PSE, including standards of practice, credentialing, and program accreditation, in their study. Furthermore, Grigal \& Hart (2010) have highlighted critical elements in PSE for persons with ID such as federal laws, funding, types of PSE programs for people with ID, available sample of PSE programs, components of PSE programs for people with ID, employment, and community participation for people with ID in their study.

While it is difficult to generalize the findings of a single qualitative study, however, the analytic generalizations made in the current case study may accrue benefits. Researchers interested in PSE for students with ID can further carryout research on the US experience from perspectives not discussed in this study. Researchers from other countries engaged in the respective area could learn from the lessons offered by the US experience to develop customized PSE 
Lessons Offered by the United States' Experience in Integrating Students with Intellectual Disability into Postsecondary Education Areej Almutairi Norimune Kawai Abeer Alharbi

programs that can successfully integrate students with ID into their systems of higher education.

\section{Lessons offered by the US experience}

Other countries that have not yet established PSE programs for persons with ID may benefit from the US experience as following:

- Other countries can plan their own programs based on their cultures or other considerations along with adopting the various positives of the PSE programs conducted in the US.

- Other countries could also start creating these programs based on the resources available in the US, which can serve as a starting point in meeting the needs of people with ID.

- Funding for these programs is very expensive, but these countries can start with the funds that are available with them. For example, it is a good way to start implementing one or two PSE programs for people with ID as experimental programs to discover the challenges that these programs face and to determine the adequate funding needed for such programs. This step can pave the path for the designing of these programs in the future by these other countries. The US experience helps those in charge of the programs to know the specific needs for the designing of these programs, know the challenges that they may face, and know the solutions to overcome these challenges.

- Although there are a variety of international laws and legislations that protect the rights of persons with ID, we believe that in addition to following these international laws, each country should enact its own laws and legislations that protect these persons. Gadow and MacDonald (2019) pointed out that PSE programs for students with ID vary from one country to another based on local policy and funding status, which affects the direction of any inclusive education initiative. Moreover, the culture differs from one country to another, what is important in one country may not be equally important in another country. For example, some middle eastern countries separate boys and girls in schools or vocational centers as an Islamic 
value. As a result, this is taken into consideration by most of the Islamic countries during the designing of a program.

- Obstacles encountered by an experienced country like the US with PSE programs can help other countries that have not established PSE programs know the nature of these programs, needs, and difficulties, which will save the time and efforts of these countries in preparing such programs.

- The types of PSE programs needed to combine efforts between multiple sectors of a country in order for the programs to work efficiently for the benefit of people with ID.

- While it is important to learn from other experiences, however, we also think that it is not a genuine idea to imitate others without making any contributions to the field of PSE for persons with ID. Therefore, we recommend other countries that have not established PSE programs for ID persons, to document their efforts and experiences related to these programs. This can be either the difficulties, challenges, or achievements through publishing research and reports, which could offer valuable insights to other countries in preparing such type of programs in the future.

- These programs should undergo continuous evaluation to maintain their work effectively and have to be revised with respect to the things that need to be changed, canceled, or updated to improve the quality of such programs.

- Making relationships and partnerships with other PSE programs is an important step, which the other countries could draw benefits from by relying on the experiences of the US.

\section{Implications of the study}

The discussion of PSE for students with ID raises several questions concerning the important aspects of policy, practice, and studies in this area (Grigal et al., 2010). The implications of this study are as follows:

- Policymakers interested in integrating students with ID into PSE should begin by establishing a supportive legislative foundation. 
Lessons Offered by the United States' Experience in Integrating Students with Intellectual Disability into Postsecondary Education Areej Almutairi Norimune Kawai Abeer Alharbi

Grigal et al. (2011) emphasize the critical role played by leaders at state and local levels in various education and disability service agencies. They also call for collaboration between agencies to build constituent networks, develop a fundamental infrastructure, and make necessary contacts between organizations to create higher educational opportunities for students with ID. To this end, leaders should take time to find resources, options, and available opportunities in their areas. Further, very few studies have been conducted on leaders and administrators of PSE for students with ID. There is an essential need to document leadership and administrative experiences in order to guide policymakers and leaders from other nations that have not established PSE programs for persons with ID.

- Other countries can learn from the lessons offered by the US's experience presented in this study to create their own higher education programs and fast-track their efforts to include students with ID into PSE.

- Countries that have already taken steps to integrate students with ID into PSE should share their expertise in this regard for the benefit of others worldwide.

\section{Limitations of the study}

Grigal et al. (2010) highlight a crucial point regarding the progress indicators for a project or study that has been carried out by others. They believe that using signs of success or achievement may be misleading and not portray the real situation. We should, therefore, not rely solely on studies and research found online or in print to recommend substantial changes in practice. Moore (2014) reported that it is difficult to overstate the importance of quantitative data in higher education for students with ID. However, one of the limitations of this study is that it is based on secondary data, not relying on first-hand observations made in the field to determine what is realistic and practical.

There are insufficient studies that focus on the US experience of integrating students with ID into PSE. Most of the available studies 
focus on the theoretical methods and practices, with very few exploring the process of the evolution of inclusive PSE in the US. Moore (2014) noted that most of the research conducted in the field of higher education for students with ID provides anecdotal evidence regarding specific programs or student experience. Therefore, we found it challenging to find sources that outline this specific experience in a precise and practical fashion for the current study.

Another limitation of this study is that the researchers' views on what the US has achieved in PSE for students with ID may carry elements of biases owing to our research experiences of working on the subject of PSE for persons with ID earlier. However, the study ensures that the issues and shortcomings that impede the progress of PSE programs in the US experience are also highlighted. While is true that other countries such as Canada, Australia, and Italy have also been successful in including students with ID in PSE, there are however, few published studies available concerning these countries' interventions. While these countries may have had significant success in integrating students with ID into inclusive university education, the information on their experiences is not readily available. Another limitation of this study is that a discussion on the progress made by other countries is beyond the scope of this survey. Lastly, although the researchers were fully immersed in the process of obtaining data and categorizing the data to avoid any bias, biases might have occurred during the stage of collecting and analyzing data.

\section{Conclusion}

Initiatives to create opportunities for persons with ID to pursue higher education, claim rights, and believe in their abilities require diligence and acceptance of failure amidst success. It took 20 years for the targeted legislation in the US to integrate students with ID into PSE for positive results to be observed (Walker, 2014); with their being more room for progress. As Grigal, Hart, and Lewis (2012) stated, progress made in PSE for students with ID has opened up an opportunity to start a conversation in this area and hopefully may continue for a long time. The current article is an attempt to bring 
Lessons Offered by the United States' Experience in Integrating Students with Intellectual Disability into Postsecondary Education Areej Almutairi Norimune Kawai Abeer Alharbi

out the experience of the US in integrating students with ID into PSE. We bring out the lessons offered by the US experience by focusing on various aspects, namely educational laws supporting PSE for people with ID in the US, financial support for students with ID in the US, status of research in the field, and the issues PSE systems face when integrating students with ID. The lessons offered by the US' experience of inclusivity since the 1970s is something that is worthy of consideration (Grigal et al., 2019) to develop more effective PSE programs for students with ID. 


\section{References}

Brantlinger E, Jimenez R, Klingner J, Pugach M, Richardson V. (2005). Qualitative studies in special education. Exceptional Children. 71(2),195-207. doi:10.1177/001440290507100205.

Braun, V., \& Clarke, V. (2006). Using thematic analysis in psychology. Qualitative Research in Psychology. 3(2), 77-101. doi:10.1191/1478088706qp063oa

Brewer, R., \& Movahedazarhouligh. S. (2019). Students with intellectual and developmental disabilities in inclusive higher education: perceptions of stakeholders in a first-year experience. International Journal of Inclusive Education. doi: 10.1080/13603116.2019.1597184

Cook, A., Hayden, L., Wilczenski, F., \& Poynton, T. (2015). Increasing access to postsecondary education for students with intellectual disabilities. Journal of College Access, 1(5), 42-55. Retrieved

from http://scholarworks.wmich.edu/jca/vol1/iss1/5

Francis, L., Gordon, S., Kliethermes, A., Regester, A., Baldini, D., \& Grant, A. (2018). Developing and implementing a postsecondary education program for young adults with intellectual and developmental disabilities: Processes and procedure. Teacher Educators' Journal, 11,134-156. Retrieved from https://files.eric.ed.gov/fulltext/EJ1174734.pdf

Gadow, F., \& MacDonald, J. (2019). Scope, challenges, and outcomes of an inclusive tertiary university initiative in Australia. In P. O’Brien, M. L. Bonati, F. Gadow, \& R. Slee (Eds.), People with intellectual disability experiencing university life: Theoretical underpinnings, evidence and lived experience (pp. 129-140). Koninklijke Brill, NV: Leiden. 
Lessons Offered by the United States' Experience in Integrating Students with Intellectual Disability into Postsecondary Education Areej Almutairi Norimune Kawai Abeer Alharbi

Gibbons, M., Cihak, F., Mynatt, B., \& Wilhoit, E. (2015). Faculty and student attitudes toward postsecondary education for students with intellectual disabilities and autism. Journal of Postsecondary Education and Disability, 28(2), 149-162. Retrieved

from https://files.eric.ed.gov/fulltext/EJ1074661.pdf

Griffin, M., \& Papay, C. (2017). Supporting students with intellectual and developmental disabilities to attend college. Teaching Exceptional Children, 49(6), 411-419. Retrieved from https://thinkcollege.net/sites/default/files/files/resources/Gri ffin\%20Papay\%202017 CEC.pdf

Grigal, M., \& Hart, D. (2010). Think college! Postsecondary education options for students with intellectual disabilities (2nd ed.). Baltimore, MD: Paul H. Brookes Publishing Co.

Grigal, M., \& Papay, C. (2018). The Promise of postsecondary education for students with intellectual disability. New Directions for Adult and Continuing Education, 160, 77-88. Retrieved from https://doi.org/10.1002/ace.20301

Grigal, M., Hart, D., \& Lewis, S. (2010). A prelude to progress: Postsecondary education and students with intellectual disabilities. Think College Insight Brief, 23(3), 4. Retrieved from

https://thinkcollege.net/sites/default/files/files/resources/Ins ight 12 web F.pdf

Grigal, M., Hart, D., \& Lewis, S. (2012). A prelude to progress: The evolution of postsecondary education for students with intellectual disabilities. Think College Insight Brief, 12. Boston, MA: University of Massachusetts Boston, Institute for Community Inclusion. Retrieved from https://thinkcollege.net/sites/default/files/files/resources/Ins ight 12 web F.pdf 
Grigal, M., Hart, D., \& Papay, C. (2019). Inclusive higher education for people with intellectual disability in the United States: An overview of policy, practice, and outcomes. In P. O'Brien, M. L. Bonati, F. Gadow, \& R. Slee (Eds.), People with intellectual disability experiencing university life: Theoretical underpinnings, evidence and lived experience (pp. 69-97). Koninklijke Brill, NV: Leiden.

Grigal, M., Hart, D., \& Weir, C. (2011). Framing the future: A standards-based conceptual framework for research and practice in inclusive higher education. Think College Insight Brief, 10. Boston, MA: University of Massachusetts Boston, Institute for Community Inclusion. Retrieved from https://thinkcollege.net/sites/default/files/files/resources/Ins ight10new D3.pdf

Grigal, M., Hart, D., \& Weir, C. (2012). A survey of postsecondary education programs for students with intellectual disabilities in the United States. Journal of Policy and Practice in Intellectual Disabilities, 9(4), 223-233. Retrieved from https://doi.org/10.1111/jppi.12012

Grigal, M., Hart, D., \& Weir, C. (2013). Postsecondary education for people with intellectual disability: Current issues and critical challenges. Inclusion, 1(1), 50-63. Retrieved from https://doi.org/10.1352/2326-6988-1.1.050

Hart, D., Grigal, M., \& Weir, C. (2010). Expanding the paradigm: Postsecondary education options for individuals with autism spectrum disorder and intellectual disabilities. Focus on Autism and Other Developmental Disabilities, 25(3), 134-150. doi: $\underline{\text { http://doi.org/10.1177/1088357610373759 }}$ 
Lessons Offered by the United States' Experience in Integrating Students with Intellectual Disability

Jester, L. (2016). An exploration of postsecondary education programs for students with intellectual disabilities in public universities and colleges in Florida (Unpublished doctoral dissertation). The University of Florida, FL. Retrieved from http://stars.library.ucf.edu/etd/5181

Jones, M., Boyle, M., May, C., Prohn, S., Updike, J., \& Wheeler, C. (2015). Building inclusive campus communities: A framework for inclusion. Think College Insight Brief, 26. Boston, MA: University of Massachusetts Boston, Institute for Community Inclusion.

Retrieved

from https://thinkcollege.net/sites/default/files/files/resources/26 inclusivecommunities F 0.pdf

Kelley, K., \& Westling, D. (2019). Teaching, including, and supporting college students with intellectual disabilities. New York: Routledge.

Kleinert, H. L., Jones, M. M., Sheppard-Jones, K., Harp, B., \& Harrison, E. M. (2012). Students with intellectual disabilities going to college? Absolutely! Teaching Exceptional Children, 44(5), 2635. doi: https://doi.org/10.1177\%2F004005991204400503

Mercier, K. (2017). Students with intellectual disabilities accessing postsecondary education settings: Promoting education equity: Seeing students for their ability first and supporting their development as contributing members into a diverse society (Published doctoral dissertation). Brandman University, CA. Retrieved from https://digitalcommons.brandman.edu/cgi/viewcontent.cgi?a $\underline{\text { rticle}=1100 \& \text { context }=e d d \text { dissertations }}$

Merriam, S. B., Tisdell, E., J. (2016). Qualitative research: A guide to design and implementation (4th ed.). San Francisco, CA: Jossey-Bass. 
Moore, E. J. (2014). Postsecondary inclusion for individuals with an intellectual disability: A comparative case study (Unpublished master's thesis). Grand Valley State University, MI. Retrieved from http://scholarworks.gvsu.edu/theses/689

National Parent Center on Transition and Employment. (2019). Inclusive postsecondary education for students with intellectual disabilities. Retrieved from

https://www.pacer.org/transition/learningcenter/postsecondary/college-options.asp

Papay, C., Trivedi, K., Smith, F. A., \& Grigal, M. (2017). One year after exit: A first look at outcomes of students who completed TPSIDs. Think College Fast Fact, 17, 1-2. Retrieved from https://thinkcollege.net/sites/default/files/files/resources/FF 17 R.pdf

Plotner, A. J., \& Marshall, K. J. (2014). Navigating university policies to support postsecondary education programs for students with intellectual disabilities. Journal of Disability Policy Studies, 25(1), 48-85. doi: https://doi.org/10.1177\%2F1044207313514609

Plotner, A. J., \& Marshall, K. J. (2015). Postsecondary education programs for students with an intellectual disability: Facilitators and barriers to implementation. Intellectual and Developmental Disabilities Journal, 53(1), 58-69. doi: https://doi.org/10.1352/1934-9556-53.1.5

Scior, K. (2011). Public awareness, attitudes and beliefs regarding intellectual disability: A systematic review. Research in Developmental Disabilities, 32(6), 2164-82. doi: https://doi 10.1016/j.ridd.2011.07.005 
Lessons Offered by the United States' Experience in Integrating Students with Intellectual Disability into Postsecondary Education Areej Almutairi Norimune Kawai Abeer Alharbi

Snyder, T. D., \& Dillow, S. A. (2011). Digest of education statistics, 2010 (NCES 2011-015). National Center for Education Statistics, Institute of Education Science, U.S. Department of Education, Washington, DC. Retrieved from https://files.eric.ed.gov/fulltext/ED518987.pdf

Think College National Coordinating Center. (2019). Higher education access for students with intellectual disability in the United States. Think College Snapshot. Retrieved from https://thinkcollege.net/sites/default/files/files/resources/Sn apshot Jan2019.pdf

Tyler, T. R. (1990). Why people obey the law. Chelsea, MI: Yale University Press, New Haven and London.

Walker, K. (2014). Comparing American disability laws to the convention on the rights of persons with disabilities with respect to postsecondary education for persons with intellectual disabilities. Northwestern Journal of International Human Rights, 12(1), 115-131. Retrieved from https://scholarlycommons.law.northwestern.edu/njihr/vol12/ iss $1 / 5$

Yin, R. K. (2018). Case study research and applications: Design and methods (6th ed.). Thousand Oaks, CA: SAGE. 